\section{ETHNIC VARIATION IN OT INTERVAL AMONG HIGHLY TRAINED ATHLETES}

doi:10.1136/heartjnl-2011-300198.49

${ }^{1} \mathrm{H}$ Raju, ${ }^{1} \mathrm{M}$ Papadakis, ${ }^{2} \mathrm{~V}$ Panoulas, ${ }^{2} \mathrm{~J}$ Rawlins, ${ }^{2} \mathrm{~S}$ Basavarajaiah, ${ }^{1} \mathrm{~N}$ Chandra, ${ }^{1} \mathrm{E}$ R Behr, 'S Sharma. ${ }^{1}$ St George's University of London, London, UK; ${ }^{2}$ University Hospital Lewisham, London, UK

Background Studies in Caucasian (white) athletes indicate that a significant proportion exhibit an isolated prolonged corrected OT interval (QTc), raising concerns for potentially false diagnoses and disqualification from competitive sport. The prevalence of prolonged OTc interval in athletes of African/Afro-Caribbean (black) descent is unknown. However, this ethnic group generally exhibits a high proportion of ECG repolarisation changes and increased left ventricular wall thickness, that may impact on QTc.

Aim We aimed to assess the impact of ethnicity on OTc in young elite athletes.

Methods We assessed 3035 elite athletes, aged 14-35 years, who were participating at national and international level in a variety of sporting disciplines. Athletes were evaluated with ECG and 2D echocardiography. Athletes diagnosed with structural heart disease or hypertension were excluded from analysis.

Results Demographic and cardiological results are summarised in Abstract 49 table 1. Black male athletes exhibited shorter OTc than white male athletes, but OTc was similar among black and white female athletes. Bivariate analysis revealed that none of $\mathrm{T}$ wave inversions, ST segment elevation, or left ventricular wall thickness were associated with OTc. No ethnic difference was observed in prevalence of OT prolongation, as defined by ESC Sports Consensus criteria (male $>440 \mathrm{~ms}$; female $>460 \mathrm{~ms}$ ).

Abstract 49 Table 1 Characteristics of athletes evaluated

\begin{tabular}{lllll}
\hline & $\begin{array}{l}\text { Black Male } \\
(\mathbf{n = 9 0 1 )}\end{array}$ & $\begin{array}{l}\text { White Male } \\
(\mathbf{n = 1 6 5 2 )}\end{array}$ & $\begin{array}{l}\text { Black Female } \\
(\mathbf{n}=122)\end{array}$ & $\begin{array}{l}\text { White Female } \\
(\mathbf{n}=\mathbf{3 6 0})\end{array}$ \\
\hline Mean Age, years & $22 \pm 5$ & $17 \pm 4$ & $21 \pm 5$ & $18 \pm 4$ \\
Mean Heart Rate, bpm & $61 \pm 12$ & $56 \pm 10$ & $63 \pm 10$ & $59 \pm 9$ \\
Mean QRS duration, ms & $88 \pm 14$ & $96 \pm 10$ & $84 \pm 10$ & $88 \pm 9$ \\
Mean LV wall thickness, mm & $10.6 \pm 1.6$ & $9.4^{*} \pm 1.2$ & $9.2 \pm 1.2$ & $7.9^{*} \pm 2.9$ \\
ST segment elevation, n (\%) & $570(63.3 \%)$ & $406(24.6 \%)$ & $20(16.3 \%)$ & $64(17.8 \%)$ \\
T wave inversions, n (\%) & $204(22.6 \%)$ & $66^{*}(4.0 \%)$ & $18(14.6 \%)$ & $15^{*}(4.2 \%)$ \\
Mean OTc (Bazett's), ms & $393 \pm 26$ & $404^{*} \pm 20$ & $407 \pm 25$ & $412 \pm 27$ \\
OTc $>440 \mathrm{~ms}, \mathrm{n}(\%)$ & $20(2.2 \%)$ & $49(3.0 \%)$ & $13(10.6 \%)$ & $39(10.9 \%)$ \\
OTc $>460 \mathrm{~ms}, \mathrm{n}(\%)$ & $4(0.4 \%)$ & $7(0.4 \%)$ & $1(0.8 \%)$ & $5(1.4 \%)$ \\
\hline
\end{tabular}

Means presented as mean $+\mathrm{SD}$.

${ }^{*} p<0.001$ white vs black athletes.

Conclusion Despite demonstrating a higher prevalence of repolarisation changes and morphological left ventricular hypertrophy, black athletes do not exhibit a longer QTc than white counterparts. Based on ESC Sports Consensus criteria, prevalence of a long QTc in black and white athletes is similar, obviating the need for ethnicity specific criteria for defining a long QTc.

\section{DIAGNOSTIC ROLE OF EXERCISE TOLERANCE TESTING IN FAMILIAL PREMATURE SUDDEN CARDIAC DEATH}

doi:10.1136/heartjnl-2011-300198.50

H Raju, M Papadakis, R Bastiaenen, A Zaidi, N Chandra, M Muggenthaler, N Spath, S Sharma, E R Behr. St George's University of London, London, UK

Background Investigation of blood relatives for evidence of an inherited cardiac condition is advocated following an unexplained sudden cardiac death (SCD).
Aim We determined the diagnostic yield of exercise tolerance testing (ETT) in investigation of inherited cardiac conditions following familial premature SCD.

Methods Between 2006 and 2010, we evaluated 308 blood relatives of 148 SCD victims, who completed at least 3 min of the Bruce protocol. ETTs were analysed for: QT prolongation; Brugada type 1 pattern; ST depression: blood pressure (BP) response; multiple ventricular ectopics or arrhythmia. Individual pathological phenotypes were determined by a combination of 12-lead ECG, echocardiogram, 24-h holter monitor, with additional MRI, CT coronary angiography and genetic mutation analysis, as appropriate.

Results Thirty (9.8\%) patients had an abnormality during ETT, details of which are summarised in Abstract 50 figure 1. All ETTs with abnormal QT prolongation and dynamic Brugada pattern were associated with diagnoses of long OT syndrome and Brugada syndrome respectively. An example of dynamic Brugada phenotype is given in Abstract 50 figure 2. Ventricular ectopy was seen in 15 patients, of whom 5 demonstrated phenotypic cardiomyopathy or channelopathy on further investigations. No patients with significant ST depression had evidence of coronary abnormalities on imaging. No hypotensive BP response was seen, but exertional hypertension was associated with systemic hypertension.

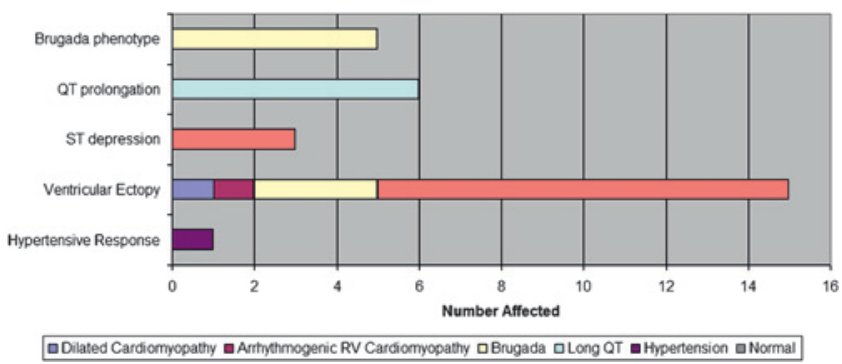

Abstract 50 Figure 1 ETT abnormalities and associated diagnoses at familial evaluation.

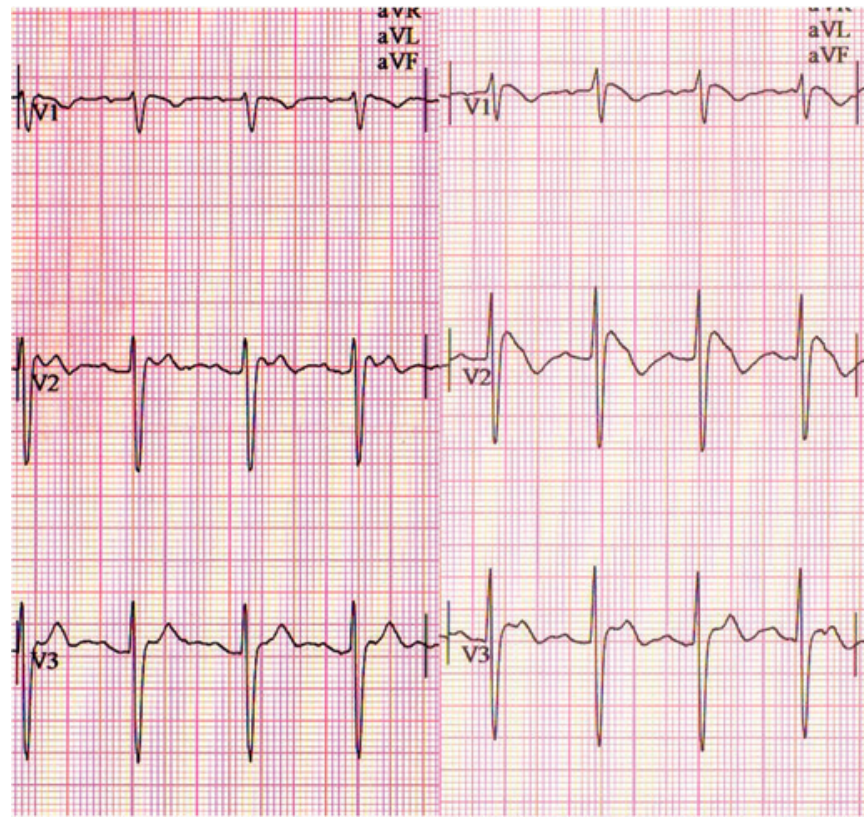

Abstract 50 Figure 2 Exercise tolerance test demonstrating dynamic Brugada ECG pattern. Stage 1 of Bruce protocol exercise (left) and postexercise recovery (right).

Conclusion The ETT is a useful diagnostic adjunct when evaluating relatives of victims of premature SCD. Reliable diagnostic indicators include inappropriate OT prolongation and dynamic Brugada 
pattern. Ventricular ectopy is non-specific, but is associated with both cardiomyopathic and channelopathic processes in a significant minority. ST segment depression, however, is unhelpful and should be viewed in the context of the patient's cardiovascular risk profile.

\section{LOW-DOSE SODIUM NITRITE RELIEVES MYOCARDIAL ISCHAEMIA IN PATIENTS WITH CORONARY ARTERY DISEASE: A TARGETED NO-DONOR EFFECT}

doi:10.1136/heartjnl-2011-300198.51

${ }^{1} \mathrm{~T}$ E Ingram, ${ }^{2} \mathrm{R}$ A Bleasdale, ${ }^{2} \mathrm{C}$ Templeton, ${ }^{2} \mathrm{C}$ Williams, ${ }^{1} \mathrm{~A}$ Margulescu, ${ }^{1} \mathrm{~A}$ G Fraser, ${ }^{1} \mathrm{P}$ E James. ${ }^{1}$ Cardiff University, Cardiff, UK; ${ }^{2}$ Royal Glamorgan Hospital, Llantrisant, UK

Introduction Sodium nitrite $\left(\mathrm{NaNO}_{2}\right)$ became a popular means of treating angina in the 19th century, as its stable chemical structure allowed for cheap preparation and easy storage. However, the effects were slow and unpredictable and so it fell out of favour as more potent and faster-acting agents became available, (eg, organic nitrates). Recent in vitro evidence shows that nitrite $\left(\mathrm{NO}_{2}^{-}\right)$exhibits an enhanced vasodilator effect in hypoxia; an environmental modification which encourages its reduction to nitric oxide (NO). Therefore $\mathrm{NaNO}_{2}$ could potentially be an anti-ischaemic agent at much lower doses than those used historically, and be without the adverse side effects associated with organic nitrates (eg, systemic hypotension and tachyphylaxis).

Method A double-blind, placebo-controlled, cross-over study was performed in 10 subjects with proven myocardial ischaemia documented by exercise tolerance testing and coronary angiography. Two dobutamine stress echocardiography (DSE) studies were performed on each subject: one with $0.9 \%$ saline and one with $\mathrm{NaNO}_{2}$, $1.5 \mu \mathrm{mol} / \mathrm{min}$ for $20 \mathrm{~min}$. This dose of $\mathrm{NaNO}_{2}$ has previously been shown to be inert in normoxia but to vasodilate hypoxic tissue. Myocardial ischaemia was identified by the peak systolic velocity (PSV) response during DSE in a six basal-wall segment model of the left ventricle. Using placebo study data-set, walls were classified into tertiles: the lowest tertile of responders of PSV to an increase in heart rate $(\Delta \mathrm{HR})$ labelled ischaemia $(\mathrm{n}=18)$ and the upper tertile control $(n=18)$. Data was divided into four groups according to the study-infusion received and the myocardial-wall examined: saline/ ischaemia, $\mathrm{NO}_{2}^{-}$/ischaemia, saline/control and $\mathrm{NO}_{2}^{-}$/control.

Results Data from each stage of each DSE was plotted on a scatter plot graph with change in $(\Delta \mathrm{HR})$ on the $\mathrm{x}$-axis and corresponding change in PSV $(\triangle \mathrm{PSV})$ on the $y$-axis (increase in both values compared to baseline), see Abstract 51 figures 1 and 2. Linear regression analysis of the saline/ischaemia group was lower than the $\mathrm{NO}_{2}{ }^{-}$/ischaemia group, with no overlap in their $95 \% \mathrm{CI}$, see Abstract 51 figure 1. In addition, the linear regression gradient of the $\mathrm{NO}_{2}^{-}$/ ischaemia group was similar to the saline/control and the $\mathrm{NO}_{2}^{-}$/control gradient, see Abstract 51 figure 2. The peak-dose dobutamine values

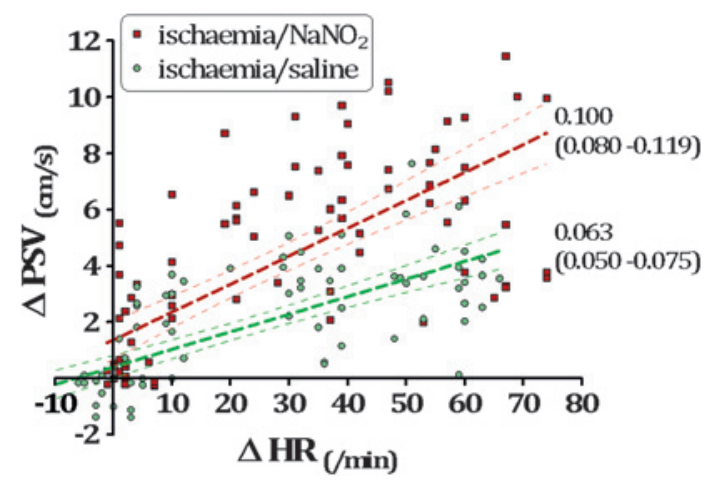

Abstract 51 Figure 1 of $\Delta \mathrm{PSV} / \Delta \mathrm{HR}$ were different in the saline/ischaemia group compared to the three other groups (ie, saline/ischaemia $=3.7 \pm 0.6 \mathrm{~cm} / \mathrm{s} / \mathrm{s}$, $\mathrm{NO}_{2}{ }^{-} /$ischaemia $=8.2 \pm 1.0 \mathrm{~cm} / \mathrm{s} / \mathrm{s}$, saline $/$ control $=10.5 \pm 1.1 \mathrm{~cm} / \mathrm{s} / \mathrm{s}$, $\mathrm{NO}_{2}{ }^{-}$/control $=8.4 \pm 0.7 \mathrm{~cm} / \mathrm{s} / \mathrm{s} ; \mathrm{p}<0.01$, repeated-measures ANOVA with Bonferroni post-test). No difference was present between the three other groups.

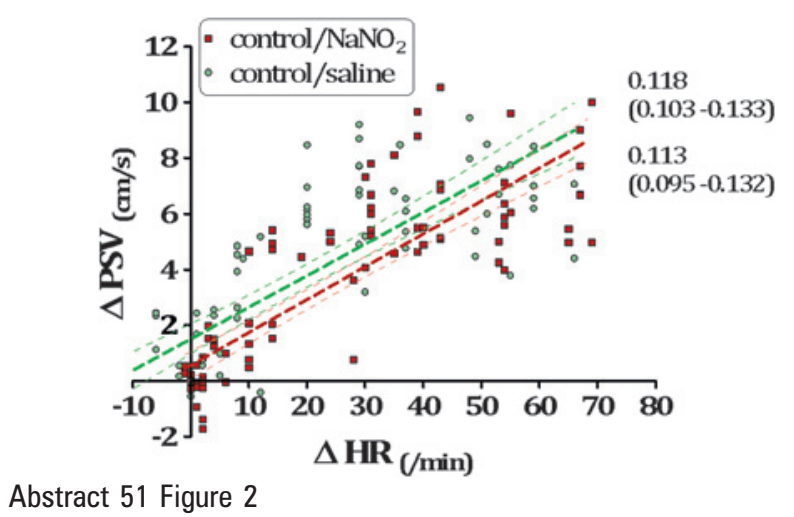

Conclusions Low-dose $\mathrm{NaNO}_{2}$ delivers a therapeutic effect to ischaemic myocardial tissue in the absence of a vasodilator effect on normoxic tissue. This is the first study in patients to demonstrate a targeted vasodilator effect of $\mathrm{NO}_{2}^{-}$to tissues in need only.

\section{BRAIN NATRIURETIC PEPTIDE PREDICTS ALL CAUSE MORTALITY IN PATIENTS WITH TYPE 2 DIABETES AND NORMAL EJECTION FRACTIONS}

doi:10.1136/heartjnl-2011-300198.52

${ }^{1} \mathrm{~B}$ R Szwejkowski, ${ }^{1} \mathrm{D}$ H J Elder, ${ }^{2} \mathrm{~A}$ Dawson, ${ }^{1} \mathrm{~A}$ D Struthers. ${ }^{1}$ University of Dundee, Dundee, UK; ${ }^{2}$ Department of Cardiology, NHS Tayside, Dundee, UK

Introduction The use of brain naturetic peptide (BNP) to predict outcome in patients with normal ejection fractions (EF) and type 2 diabetes (T2DM) is understudied. Only three previous studies have specifically addressed the question as to whether BNP adds prognostic information in T2DM. There appears to be a link between survival and BNP in T2DM, however these studies included small numbers of patients and did not fully exclude left ventricular systolic dysfunction (LVSD). We therefore studied the 5-year survival in a cohort of 500 T2DM patients prospectively phenotyped with echocardiography.

Methods 500 patients with T2DM where studied with echocardiography between April 2002 and October 2003. Patients were recruited from the diabetes clinics at Ninewells Hospital, Dundee. Transthoracic echocardiography was performed by one trained operator and left ventricular (LV) assessment was performed using modified biplane Simpson's method over three cycles. We excluded individuals with EF of $<55 \%$. Follow-up data was linked via the Health Informatics Centre (HIC), to mortality data, laboratory test data, hospitalisation, and prescribing via the community health index (CHI) number. Cox proportional hazards model was used to examine the effects of BNP (bedside stick measurement) measure on all-cause mortality using age, sex, smoking status, hypertension, IHD, duration of diabetes, and diabetic drug prescription as co-variants. Outcome was all cause mortality.

Results In total we followed 316 patients over 8 years. 56 patients died over this time. After adjusting for confounding factors we have shown that for every 10-unit increase in BNP there is a $6 \%$ increased risk of death. HR 1.06 (95\% CI 1.02 to 1.10$)(p=<0.01)$.

Conclusions In patients with normal EF, BNP is an independent predictor of death in a cohort of T2DM patients. Although more research is needed, BNP may become an important tool in risk stratifying T2DM patients in the future. 